Elsevier required licence: (C) <2017>. This manuscript version is made available under the CC-BY-NC-ND 4.0 license http://creativecommons.org/licenses/by-nc-nd/4.0/ 


\section{Phenol rejection by cellulose triacetate and thin film composite forward osmosis} membranes

5 6

${ }^{a}$ Laboratory for Membrane Materials and Separation Technology, Shanghai Advanced Research Institute, Chinese Academy of Sciences, Shanghai 201203, China

${ }^{b}$ University of Chinese Academy of Sciences, Beijing 100049, China

'School of Physical Science and Technology, ShanghaiTech University, Shanghai 201210, China

${ }^{d}$ Strategic Water Infrastructure Laboratory, School of Civil, Mining and Environmental Engineering, University of Wollongong, Wollongong, NSW 2522, Australia 


\section{Highlights}

19 1. High phenol adsorption to CTA membrane resulted in low rejection

20 2. Phenol rejection by TFC PA membrane was higher than CTA one in both FO and RO modes

21 3. Phenol rejection in RO mode could be mathematically simulated

22 4. Phenol rejection in FO mode was higher than in RO mode due to retarded forward diffusion

23 5. Phenol rejection can be enhanced by increasing the feed $\mathrm{pH}$ 


\section{Abstract}

This study aims to elucidate the separation of phenol by reverse osmosis (RO) and forward osmosis (FO)

27 modes and propose strategies to enhance phenol rejection by these two processes. The results show that 28 phenol rejection was strongly influenced by water flux, membrane materials, membrane structure, modes 29 of operation, and feed solution chemistry (i.e. $\mathrm{pH}$ ). The relationship between phenol rejection and water 30 flux was demonstrated by the irreversible thermodynamic model which could accurately simulate phenol 31 rejection as a function of water flux. At $\mathrm{pH} 7$, phenol rejection by cellulose acetate (CTA) membranes was 32 negligible while the thin film composite (TFC) polyamide (PA) membranes exhibited much higher phenol 33 rejection. Through a systematic static adsorption experiment, results in this study show that phenol 34 adsorption to CTA material was about 20 times higher than that to PA material. Thus, the observed higher 35 phenol rejection by TFC PA compared to CTA membranes was attributed to the significantly higher affinity 36 of phenol toward CTA and the sorption diffusion transport mechanism of phenol through the membrane. In 37 particular, a TFC PA membrane specific for FO operation was prepared in this study. In FO mode, the 38 tailor-made TFC PA membrane showed a slightly higher phenol rejection and a much higher water permeability compared to the commercial membrane. At the same water flux and solution $\mathrm{pH}$, phenol rejection in FO mode was consistently higher than in RO mode. This observation could possibly be attributed to the reverse diffusion of draw solutes in the FO mode which hinders the forward diffusion of phenol through the membrane. A significant increase in phenol rejection was achieved by increasing the feed $\mathrm{pH}$ above the dissociation constant of the compound. 


\section{Introduction}

Phenol is both an important precursor material and a toxic by-product in many industrial processes including paper manufacturing, oil refining, coking, petrochemical, and pharmaceutical production $[1,2]$. If released into the environment, phenol can accumulate in ground water, soil, or surface water [3]. Phenol compounds and derivatives are harmful for living organisms even at a low concentration, thus are considered as priority pollutants [4]. Many chemical, physical-chemical, and biological methods have been utilized in treating phenol-containing wastewater, such as chemical methods including chemical oxidation, photo-oxygenation, supercritical water oxidation, and physical-chemical methods including solvent extraction, incineration, adsorption, steam stripping processes, and biological method including activated sludge process [4]. To determine a suitable technology for treating the phenol-containing wastewater, several criteria should be considered: operational cost and capital investment, treatment efficiency, generation of secondary waste streams or solid, and footprints. Taking these criteria as guidelines, current chemical, physical and biological processes are not optimal yet.

Membrane technologies, mainly reverse osmosis (RO), nanofiltration (NF), have been challenged for phenol separation. Cellulose acetate membranes have been studied by several researchers in reverse osmosis process $[5,6]$. Negative rejection was reported at an operational pressure ranging from 34-104 bars at $30^{\circ} \mathrm{C}$ [7]. Higher rejection was found for TFC membranes [4, 8, 9]. In a pressure driven RO process, the rejection of small molecules was affected by several factors: size and geometric constraints, charge repulsion, and "solute-membrane affinity". The phenol compound may interact with the active coating layer based on hydrophobicity, hydrogen bonding capacity, and dipole moment [10-12]. The rejection mechanism for the low molecular weight organic solutes such as phenol and its derivatives was markedly different from that of simple aqueous salt solutions [13-17]. This strong affinity between the organic solute and the membrane material resulted in absorption of phenol and its derivatives into the membrane rather than being rejected. Recent work demonstrated that the "solute-membrane affinity" played a critical role in the rejection of trace organic contaminants [18-20], leading to a negative rejection on phenol of cellulose acetate (CA) or cellulose triacetate (CTA) [21].

RO and NF are pressure driven membrane processes [22]. For an osmotic pressure driven process, highly concentrated draw solution attracts water across the FO membrane, first the active separation layer followed by a porous support layer [23]. Very recent research work reported that FO process yielded higher 
phenol rejection due to the contribution of reverse salt diffusion [24]. Another work compared the rejection of CTA and TFC membranes treating 0.47 ppm phenol in FO and RO processes. The results indicated the rejections of CTA membranes were lower than TFC membranes in FO and RO modes, and the adsorbed mass by the CTA membranes $\left(1.07 \mu \mathrm{g} / \mathrm{cm}^{2}\right)$ was higher than that by TFC membranes $(0.75$ $\left.\mu \mathrm{g} / \mathrm{cm}^{2}\right)$ in FO mode. However, the reported static adsorption experiment of TFC membranes included both the top layer and the support layer of TFC membranes, thus the results were actually an average of the polyamide (PA) active layer and the support layer [25]. Besides, the rejection of phenol by currently available RO and FO membranes were not sufficiently high and thus further treatment might be required (e.g. integral of membrane technologies and other conventional chemical and physical treatment approaches). An improved phenol removal rate in the primary treatment stages is highly desirable to achieve the overall treatment efficiency.

Different driving forces may have different effects on phenol removal, and in turn reflecting in the removal efficiency. It is thus necessary to further understand and improve the separation performance of membranes. The correlation between retention and adsorption of phenol-like chemicals in NF membrane has been investigated before [26]. It was found that the increased adsorption of the organic matter lead to accelerated the diffusion of phenol across the membrane, hence decreased retention [26]. Based on the adsorption experiments using NF/RO membrane, the hydrophobic attraction was found to enhance the adsorption of phenolic compound on the membrane surface, and alter the rejection performance [27]. In this paper, we intended to systematically correlate the sorption of phenol in the active separating layer to the rejection in FO process. The actual rejection of phenol by both $\mathrm{RO}$ and FO membranes could be further improved. In this paper, we focus on further improvement of the removal rate of phenol using FO membranes based on the understanding of the adsorption and mass transfer of phenol in the active layer of both types of membranes. The feed was a synthetic phenol/ $\mathrm{NaCl} / \mathrm{H}_{2} \mathrm{O}$ mixture, representing the typical wastewater from the oil/gas industry. The commercial TFC FO, CTA FO, and tailor-made TFC FO membranes were selected for investigation. Irreversible thermodynamics model was utilized to simulate the performance of membranes in RO mode. Significant improvement in phenol removal in FO mode and high $\mathrm{pH}$ was found. Sorption of the active layer to the phenol was investigated based on both tailor-made TFC FO membrane and commercial membranes. Hypothesis for the increased removal performance was provided. The research provides a methodological approach for increasing the removal rate of phenolic matters from a mixture via FO membranes. 


\section{Experimental}

\subsection{Chemicals and membrane materials}

Flat sheet CTA and TFC membranes were kindly supplied from Fluid Technology Solutions (Albany, Oregon, USA). They are denoted as FTS-CTA and FTS-TFC, respectively. Phenol, N,N-dimethyl acetamide (DMAc), polyethylene glycol (PEG400), n-hexane, sodium hydroxide $(\mathrm{NaOH})$ and sodium chloride $(\mathrm{NaCl})$ were obtained from Sinopharm Chemical Reagent Co., Ltd (Shanghai, China). M-phenylenediamine (MPD) and trimesoyl chloride (TMC) were obtained from Sigma-Aldrich (Shanghai, China). These chemicals and solvents were of reagent grade. Polysulfone (PSf, P3500) was purchased from Solvay.

\subsection{Fabrication and characterization of TFC-FO membranes}

The PSf support and PA active layers were prepared by phase inversion and interfacial polymerization, respectively, as previously described in the literature. Briefly, the PSf support layer was prepared from a mixture of PSF (18 g)/ PEG-400 (8 g)/DMAC (74g). The mixture was stirred at $65{ }^{\circ} \mathrm{C}$ until a clear solution was obtained [28, 29]. After filtered, de-gassed, a film was cast (Elcometer 4340, Elcometer Asia Pte. Ltd) using a casting knife of $150 \mu \mathrm{m}$ and immersed into a water bath of $30^{\circ} \mathrm{C}$. The resulting support PSf membrane was rinsed and stored in DI water. For preparation of TFC FO membrane, an interfacial polymerization was adopted as follows: a water phase (MPD 2 wt.\%) and organic phase (TMC in hexane 0.15 wt.\%) were brought to contact at the PSf membrane top surface for 2 and $1 \mathrm{~min}$, respectively; the TFC PA membrane was cured in an oven at $95{ }^{\circ} \mathrm{C}$ for $3 \mathrm{~min}$, and stored in DI water before further analysis [28-31] .

Key membrane transport parameters include salt rejection $(R, \%)$, pure water permeability coefficient $\left(A, L / m^{2} h b a r\right)$, salt permeability coefficient $\left(B, L / m^{2} h\right)$ were determined using the standard protocol described by Cath et al., [32]. A laboratory scale cross-flow reverse osmosis system (Sterlitech Corporation) was utilized [32]. The effective membrane area was $24 \mathrm{~cm}^{2}$. The cross-flow velocity was maintained at 0.25 $\mathrm{m} / \mathrm{s}$. All experiments were conducted at $25 \pm 1^{\circ} \mathrm{C}$. The intrinsic water permeability, A, was determined by:

$$
\mathrm{A}=J_{W} / \Delta P
$$

(1)

The pure water flux, $J_{w}$, was measured by dividing the volumetric permeate rate by the membrane surface area with DI feed water under an applied trans-membrane pressure of 10 bar. Salt rejection was 
measured using $1000 \mathrm{ppm} \mathrm{NaCl}$ as the feed solution at 10 bar. The observed $\mathrm{NaCl}$ rejection, $\mathrm{R}$, was determined by Eq.(2):

$\mathrm{R}=1-\frac{c_{p}}{C_{b}}$

And the bulk feed $\left(C_{b}\right)$ and permeate $\left(C_{p}\right)$ were the salt concentrations.

\subsection{Surface characterization}

The membrane morphology was examined by a ZEISS SUPRATM 55 scanning electron microscope (SEM). Cross section samples were prepared by breaking the membrane under a cryogenic condition, followed by vacuum drying overnight at $30^{\circ} \mathrm{C}$ and then gold coating.

The membrane surface charge was characterized by a streaming electrokinetic analyzer (Surpass Anton Paar, Austria). The area of each sample was $0.2 \times 0.1 \mathrm{~cm}^{2}$ and the membranes were immobilized to the adjustable gap cell $(100 \pm 2 \mu \mathrm{m})$. $\mathrm{KCl}$ solution $(1.0 \mathrm{mmol} / \mathrm{L})$ was used as the electrolyte. $\mathrm{HCl}$ and $\mathrm{NaOH}$ were used for $\mathrm{pH}$ adjustment.

\subsection{Membrane performance in FO mode}

A stainless steel FO membrane cell with length, width and channel high of 80,30 , and $2 \mathrm{~mm}$ was used. Two variable speed gear pumps (WT3000-1FA, Baoding Qili Precision Pump Co., Ltd) were used to circulate the draw and feed solutions concurrently. Two rotameters were used to monitor the draw and feed solution flow rates. The weights of the feed and permeate reservoirs were measured by digital balances (CP4202C, OHAUS Corporation) connected to a computer. In FO mode, the feed water flowed against the dense active layer. Both draw and feed solutions flow velocities were maintained at $0.25 \mathrm{~m} / \mathrm{s}$. The FO water flux was measured by monitoring the change in the weight of the draw solution. DI water and $0.5 \mathrm{~mol} / \mathrm{L}$ $\mathrm{NaCl}$ were used as the feed and draw solutions, respectively.

The flux $\left(\mathrm{J}_{\mathrm{v}}\right)$ was calculated using the following equation:

$J_{v}=\frac{\Delta m_{d s}}{S_{m} \cdot \Delta t \cdot \rho_{w}}$

Where $\Delta m_{d s}, \Delta t, S_{m}$, and $\rho_{\mathrm{w}}$ are the mass of permeation water, time interval, effective membrane surface area, and draw solution density, respectively. The change of draw solution concentration was negligible and the ratio of water permeation to the draw solution was less than $5 \%$.

The reverse salt flux, $\mathrm{J}_{\mathrm{s}}$, of the membrane was characterized by calculating the change of salt content in the feed solution based on conductivity from Eq. (4): 
$J_{S}=\frac{V_{t} \cdot C_{t}-V_{o} \cdot C_{o}}{S_{m} \cdot \Delta t}$

(4)

Where $C_{t}$ and $V_{t}$ are the salt concentration and the volume of the feed solution at time $t$, respectively. And $C_{0}$ and $V_{0}$ are the salt concentration and the volume of the feed solution at initial time, respectively.

The solute resistivity, $\mathrm{K}$, can be determined by the following equation [33]:

$\mathrm{K}=\left(\frac{1}{J_{v}}\right) \ln \left(\frac{B+A \Pi_{D, b}}{B+A \Pi_{F, m}+J_{v}}\right)$

Where $J_{V}$ is the FO water flux, $\Pi_{D, b}$ is the bulk osmosis pressure of the draw solution, and $\Pi_{F, m}$ is thosmosis pressure at the membrane surface on the feed side. $\Pi_{F, m}$ can be calculated according to Eq. (6): $\frac{\Pi_{F, m}}{\Pi_{F, m}}=\exp \left(\frac{J_{v}}{\kappa}\right)$

The membrane structural parameter, $S$, was defined as the product of $K$ and $D$ [34].

$\mathrm{S}=K D$

The solute rejection $\mathrm{R}(\%)$ was defined as the percentage of feed solutes that were retained by the membrane as described in Eq. (8):

$\mathrm{R}=1-\frac{C_{d} \times V_{d} / V_{p}}{C_{f}}$

(8)

Where $C_{d}(p p m)$ is the phenol concentration in the draw solution at the end of each FO test, $V_{d}(L)$ is the final volume of the draw solution, $V_{p}(L)$ is the volume of the permeate, and $C_{f}(p p m)$ is the phenol concentration in the feed. $C_{d}(p p m)$ and $C_{f}(p p m)$ were determined using UV-Vis spectroscopy (Unico UV-2800). The peak value of absorbance wavelength was used to determine the concentration. The maximus absorbance wavelength of phenol was set at $270 \mathrm{~nm}$.

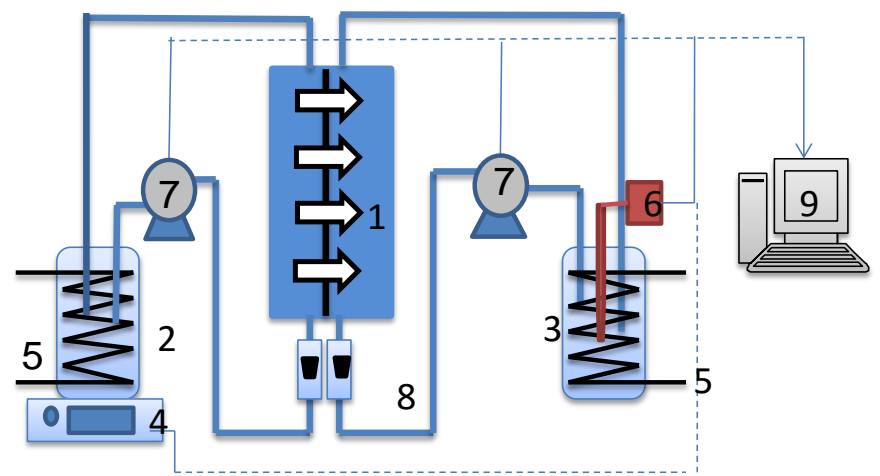

Fig. 1 Schematic diagram of the FO system. 1. membrane module; 2 . feed solution container; 3 . draw solution container; 4. balance; 5 . thermostatic bath; 6 . conductivity transmitter; 7. gear pump; 8 . flowmeter; 9. data collection and analysis system. 


\subsection{Experiments and modeling of phenol rejections in RO mode}

FTS-CTA, FTS-TFC and tailor-made-TFC membranes were evaluated using feed solutions containing 100 ppm phenol at varying sodium chloride concentrations, applied pressures, and $\mathrm{pH}$ values. After $100 \mathrm{~mL}$ of permeate had been obtained, samples were taken from both the feed and permeate for measurement of phenol concentration. Solution temperature was maintained at $25 \pm 1{ }^{\circ} \mathrm{C}$. The feed $\mathrm{pH}=11$ of the TFC membrane was adjusted by adding a small volume of $4 \mathrm{~mol} / \mathrm{L} \mathrm{NaOH}$.

Based on irreversible thermodynamic model developed by Kedem and Katchalsky [35, 36], real rejection of an RO membrane can be expressed as:

$R_{\text {real }}=1-\frac{C_{p}}{C_{m}}=\frac{\sigma(1-F)}{(1-\sigma F)}$

$\mathrm{F}=\exp \left(-\frac{(1-\sigma)}{P_{S}} J_{v}\right)$

where $\sigma, C_{p}, C_{m}, P_{s}, J_{v}$ are the reflection coefficient, the concentration of permeate, the solute concentration on the membrane surface, solute permeability coefficient, and solvent flux, respectively. $\sigma$ represents the fraction of solute reflected by the membrane in convective flow and ranges from 0 (no solute rejection) to 1 (no solute passage), while the solute permeability coefficient $\left(P_{s}\right)$ represents the effective diffusivity of a solute inside a pore [37].

Due to the concentration polarization, the solute accumulates at the membrane surface and the solute concentration on the membrane surface $\left(C_{m}\right)$ is higher than that in the feed bulk $\left(C_{b}\right)$. Therefore, the real rejection $\left(R_{\text {real }}\right)$ can be calculated from the observed rejection (Eq. 11) by taking account of the concentration polarization effect [38]:

$R_{o b s}=1-\frac{C_{p}}{C_{b}}$

$R_{\text {real }}=\frac{R_{o b s} \exp \left(J_{v} / \mathrm{k}\right)}{1+R_{o b s}\left[\exp \left(J_{v} / k-1\right)\right]}$

where $\mathrm{k}$ is the mass transfer coefficient, which is correlated to the Sherwood number (Sh) [36].

\subsection{Phenol rejection in FO mode}

FTS-CTA, FTS-TFC and tailor-made-TFC membranes were used in FO mode using the same feed 
solution described in section 2.5 for RO experiments. The temperature of the feed and draw solutions were maintained at $25 \pm 1^{\circ} \mathrm{C}$. Because FTS-CTA membranes has higher mass transfer resistance, the concentration of the $\mathrm{NaCl}$ draw solutions were in the range of $1-4 \mathrm{~mol} / \mathrm{L}$ and for FTS-TFC and tailor-made-TFC membranes, the concentrations were in the range of $0.5-4 \mathrm{~mol} / \mathrm{L}$. At a permeate volume of $10 \mathrm{~mL}$, the first samples from both feed and draw were taken, and the concentration were noted as $\mathrm{C}_{\mathrm{f}, 0}$ and $C_{d, 0}$, and the draw solution volume was noted as $V_{d, 0}$. At the permeate volume of $100 \mathrm{~mL}$, the second pair of samples were taken and the concentration were noted as $\mathrm{C}_{\mathrm{f}, \mathrm{t}}$ and $\mathrm{C}_{\mathrm{d}, \mathrm{t}}$, and the draw solution volume was noted as $\mathrm{V}_{\mathrm{d}, \mathrm{t}}$. Therefore, Eq. (8) can be written as:

$$
\mathrm{R}=1-\frac{\left(C_{d, t} \times V_{d, t}-C_{d, 0} \times V_{d, 0}\right) / V_{p}}{\left(C_{f, 0}+C_{f, t}\right) / 2}
$$

\subsection{Adsorption capacity}

Samples of the tailor-made PSf support layer, TFC membranes of $150 \mathrm{~cm}^{2}$ (length $\mathrm{x}$ width $=10 \mathrm{~cm} \times 15$ $\mathrm{cm}$ ) were immersed into a $100 \mathrm{~mL}$ phenol solution of $10 \mathrm{ppm}$. The solution was constantly agitated by a magnetic stirrer. Aqueous samples were taken at the beginning and after $24 \mathrm{~h}$ for adsorption calculation. The thickness of the PA layer was taken as $40 \mathrm{~nm}$ [39], which could be justified by SEM images of the active layer [28]. The mass of the phenol absorbed per unit area of PA layer was determined by comparing the adsorption of phenol to the TFC membrane sample (both the PSf supporting and active layer) and only the PSf supporting sample. Since the CTA membranes showed an integral structure, adsorption was accounted for to both the active and support layer.

\section{Results and discussion}

\subsection{Membranes characterization}

Fig. 2 shows the top surface and cross section SEM images of the FTS-CTA, FTS-TFC, and tailor-made-TFC membranes. The FTS-CTA membrane has a smooth surface (Supplementary Data Fig. S1 A) and is reinforced by an embedded mesh in the middle (Fig. 2A). The TFC-FTS membrane also has a smooth surface and consists of three distinctive layers: the PA active, the ultrafiltration support, and the nonwoven support (not shown) layer. Unlike the FTS-TFC membrane, the tailor-made-TFC membrane consists of a PA active layer with a rough surface of myriads of corrugation on top of a PSf support layer with finger-like 
voids in the middle and sponge porous structure at the top and bottom (Fig. 2C and 2D). It is noteworthy that the tailor-made TFC membrane does not have a nonwoven support layer.
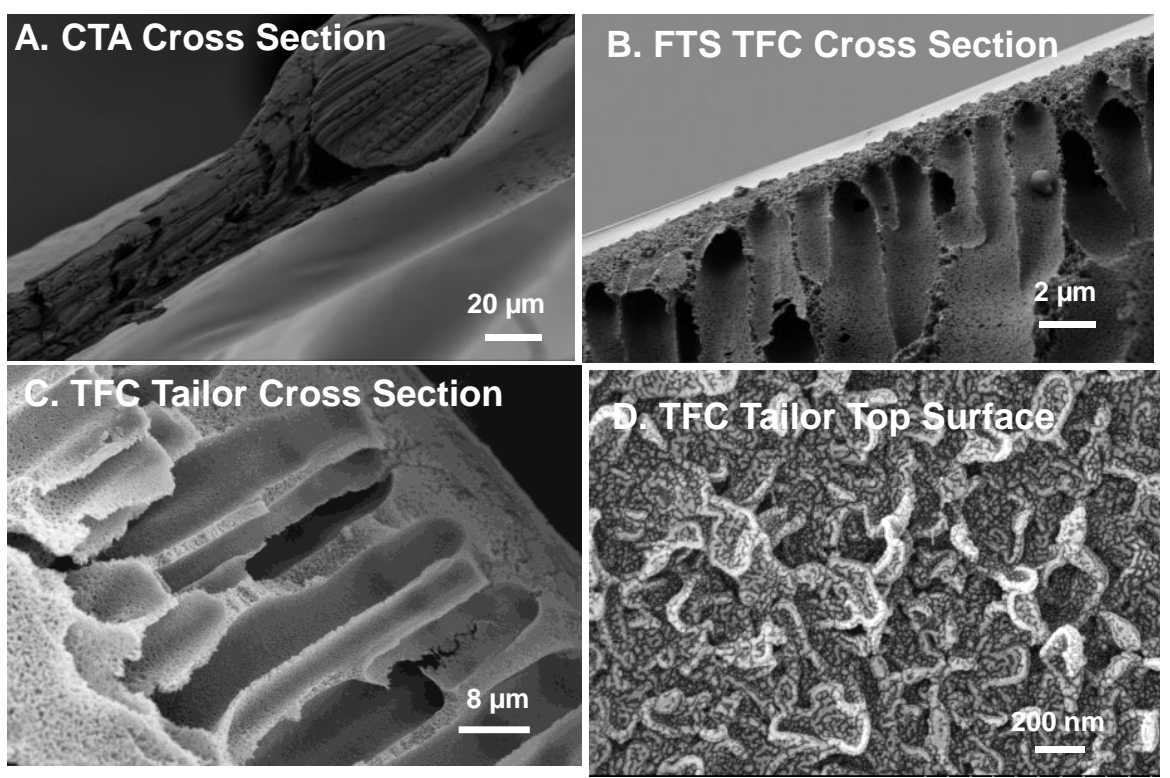

Fig. 2 SEM images of FTS-CTA, FTS-TFC, and tailor-made-TFC membranes.

Fig. 3 shows the surface charge of the FTS-CTA, FTS-TFC, and tailor-made-TFC membranes as a function of $\mathrm{pH}$. All three membranes became more negatively charged as the solution $\mathrm{pH}$ increased. Zeta potentials of membrane surface depend on the solution (e.g. $\mathrm{pH}$ and ionic strength) and the membrane polymeric chemistry. The observed highly negatively charged TFC membrane surface particularly at high $\mathrm{pH}$ is attributed to the presence of free carboxylic groups, which can be ionized at high $\mathrm{pH}$ to become negatively charged $[40,41]$. By contrast, the CTA only contains the acetyl functional groups, which are not ionizable. Thus, the negative potential of the CTA can only be attributed to the adsorption of negatively charged ions (e.g. hydroxide) to the membrane surface [41]. As a result, the CTA membrane was less negatively charged compared to both the TFS-TFC and tailor-made TFC membranes (Figure 3). 


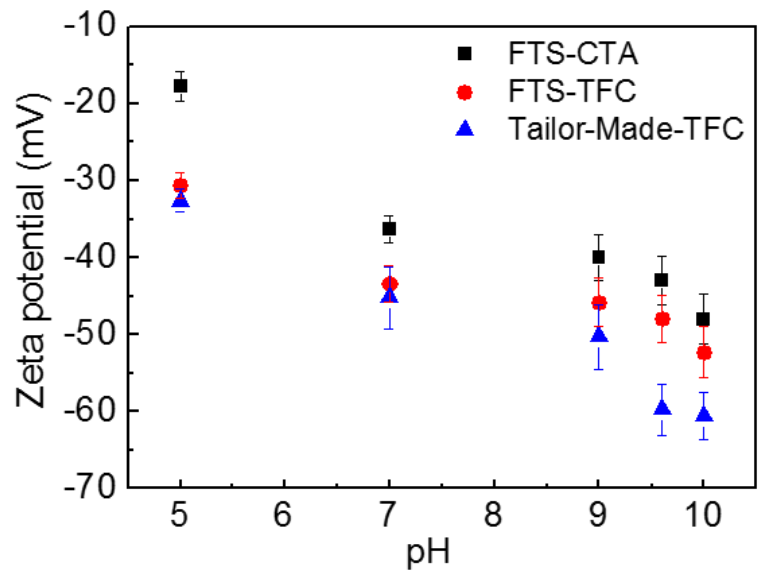

Fig. 3 The zeta potential of FTS-CTA, FTS-TFC and tailor-made-TFC as a function of $\mathrm{pH}$. The electrolyte solution contained $1 \mathrm{mmol} / \mathrm{L} \mathrm{KCl}$ (error bars show the standard deviation of three experimental measurements).

Further details about the three membranes are summarized in Table 1 . Although salt rejection by these three membranes are comparable, ranging from 96.8 to $97.8 \%$, they differ markedly from one another in terms of the structural parameter $(S)$ and water permeability (A value). The structural parameter (S) of the FTS-TFC membrane $(1,720 \mu \mathrm{m})$ was considerably higher than that of the tailor-made-TFC membranes and the FTS-CTA membrane $(170 \mu \mathrm{m})$. Unlike the tailor-made TFC membrane, which was mechanically supported by only a microporous PSf support layer, an additional nonwoven fabric layer was used in the commercially available FTS-TFC membrane. This additional nonwoven fabric layer can explain for the significantly larger $S$ value of the FTS-TFC compared to the tailor-made TFC. The CTA membrane showed a much thinner support layer of about $40 \mu \mathrm{m}$ (Fig. 2A). As a result, internal concentration polarization in the TFC membrane is more severe than that of the CTA membrane. However, a very high mass transfer resistance of the CTA membrane (low water permeability) results in a comparable water flux $\left(6.0 \pm 0.1 \mathrm{~L} / \mathrm{m}^{2} \mathrm{~h}\right)$ to that of the tailor-made-TFC membrane $\left(9.3 \pm 1.5 \mathrm{~L} / \mathrm{m}^{2} \mathrm{~h}\right)$ in the FO mode when the same draw solution of $0.5 \mathrm{~mol} / \mathrm{L} \mathrm{NaCl}$ was used (Table 1 ).

Table 1 Characteristics of tailor-made-TFC, FTS-TFC and FTS-CTA membranes

\begin{tabular}{ccccccc}
\hline Membrane & $\begin{array}{c}\mathbf{A} \\
\left(\mathbf{L} / \mathbf{m}^{\mathbf{2}} \mathbf{h} \text { bar }\right)\end{array}$ & $\begin{array}{c}\mathbf{R}_{\mathbf{N a C l}} \\
(\mathbf{\%})\end{array}$ & $\begin{array}{c}\mathbf{B} \\
\left(\mathbf{L} / \mathbf{m}^{\mathbf{2}} \mathbf{h}\right)\end{array}$ & $\begin{array}{c}\mathbf{S} \\
(\boldsymbol{\mu m})\end{array}$ & $\begin{array}{c}\text { FO flux } \\
\left(\mathbf{L} / \mathbf{m}^{\mathbf{2}} \mathbf{h}\right)\end{array}$ & $\begin{array}{c}\mathbf{J}_{\mathbf{S}} / \mathbf{J}_{\mathbf{v}} \\
(\mathbf{g} / \mathbf{L})\end{array}$ \\
\hline tailor-made-TFC & $2.57 \pm 0.04$ & $97.8 \pm 0.4$ & $0.39 \pm 0.09$ & $821 \pm 54$ & $9.3 \pm 1.5$ & $0.30 \pm 0.05$ \\
\hline FTS-TFC & $1.35 \pm 0.12$ & $96.8 \pm 0.2$ & $0.10 \pm 0.05$ & $1,640 \pm 100$ & $5.5 \pm 1.3$ & $0.27 \pm 0.05$ \\
\hline FTS-CTA & $0.38 \pm 0.01$ & $97.4 \pm 0.4$ & $0.09 \pm 0.01$ & $170 \pm 10$ & $6.0 \pm 1.0$ & $0.20 \pm 0.05$ \\
\hline
\end{tabular}


Note: $A, B$ and rejection values were determined by RO using $1000 \mathrm{ppm} \mathrm{NaCl}$ as feed under pressure of $10.0 \pm 0.1$ bar. S, Jv and $\mathrm{J}_{\mathrm{s}} / \mathrm{J}_{\mathrm{v}}$ values were obtained from $\mathrm{FO}$ test using $0.5 \mathrm{~mol} / \mathrm{L} \mathrm{NaCl}$ and deionized water as draw and feed solutions, respectively under FO mode (active layer facing the feed solution).

\subsection{Effect of salinity and $\mathrm{pH}$ in $\mathrm{RO}$ mode}

Fig. 4 showed the water fluxes and phenol rejections by the FTS-CTA, FTS-TFC, and tailor-made TFC membranes in $\mathrm{RO}$ mode at neutral $\mathrm{pH}(\mathrm{pH}=7)$ as a function of applied pressure and $\mathrm{NaCl}$ concentration in the feed. As expected, the water fluxes increased as the feed pressures increased. A slight reduction in water fluxes observed as the feed salinity increased, due to the increase in the feed osmotic pressure. Phenol rejections by the three membranes differ markedly from one another. For the CTA membrane, no phenol rejections were observed at all operational pressures. For the two TFC membranes, the rejections increased significantly as the operational pressures increased from 1.9 to 5.9 and 9.9 bars. However, above 10 bars, no further increase in phenol rejection could be observed. Since the water flux increased as the applied pressure increased, these results show that phenol rejection is a function of water. The relationship between water flux and phenol rejection will be discussed further in the next section. Fig. 4 also showed that phenol rejections of FTS-CTA, FTS-TFC and tailor-made TFC membranes were mostly independent of the $\mathrm{NaCl}$ concentration in the feed solution. The stable rejection of phenol as independent of $\mathrm{NaCl}$ concentration also confirms that the membranes were not damaged by the presence of phenol in the feed solution.

Phenol rejections by the FTS-TFC and tailor-made TFC membranes at $\mathrm{pH} 11$ were measured (Fig. 5). Since the CTA membrane is sensitive to an alkali condition [42], it was not used to evaluate phenol rejection at $\mathrm{pH} 11$. The dissociation of phenol to phenolate occurs at $\mathrm{pK} \mathrm{a}_{\mathrm{a}}=9.95$; at $\mathrm{pH}>9.95$, phenol transforms to ionic form, phenolate (Supplementary Data Fig. S2). One may take this advantage as an effective means to improve the removal rate of phenol. At $\mathrm{pH}=11$, the FTS-TFC and tailor-made TFC membranes showed minor reduction in flux comparing to the case at feed $\mathrm{pH}=7$; however, the phenol rejections increased drastically at higher $\mathrm{pH}$. Because phenolate is negatively charged, the negatively charged active PA layer (Fig. 3) repulses the matters with the same charges (charge repulsion) [43]. Since there exists both phenol and phenolate and the rejection to phenol is low, the total rejection to phenol (and phenolate) was still below $90 \%$.

The other interesting observation was the gradual reduction of the rejection as the $\mathrm{NaCl}$ concentration increasing (Fig. 5 (b) and (d)). The addition of $\mathrm{NaCl}$ or ionic strength increase can compress the Debye 
(a) FTS-CTA; $\mathrm{pH}=7$

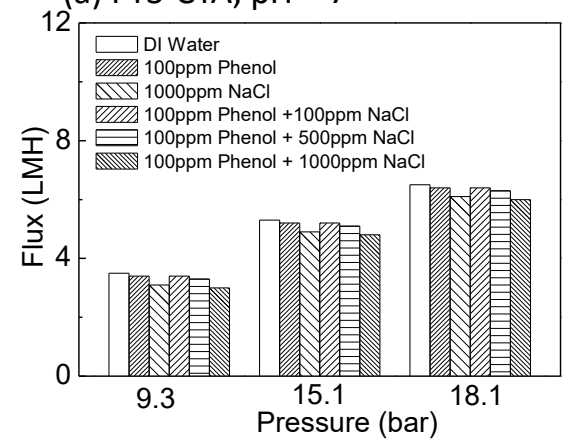

(c) FTS-TFC; $\mathrm{pH}=7$

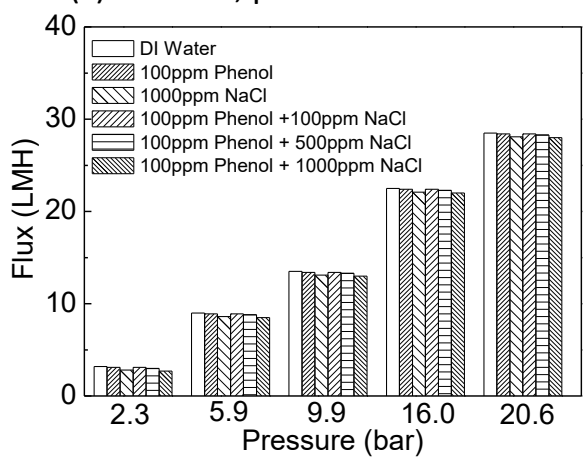

(e) Tailor-made-TFC; $\mathrm{pH}=7$

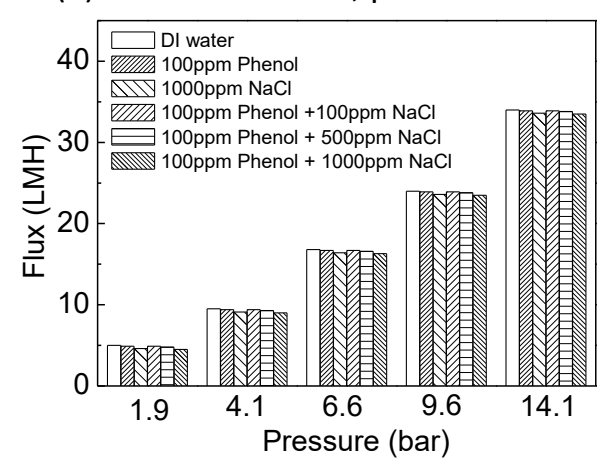

(b) FTS-CTA; $\mathrm{pH}=7$

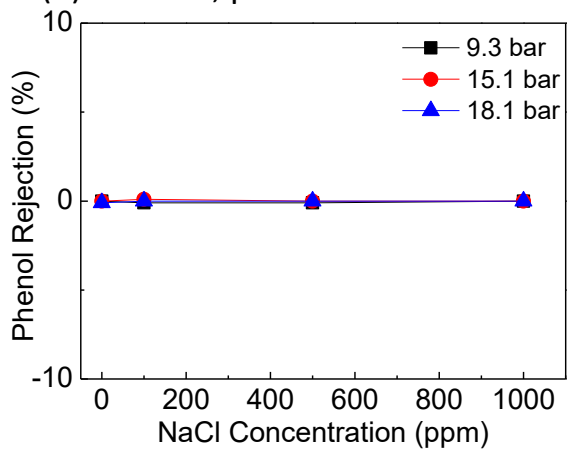

(d) FTS-TFC; $\mathrm{pH}=7$

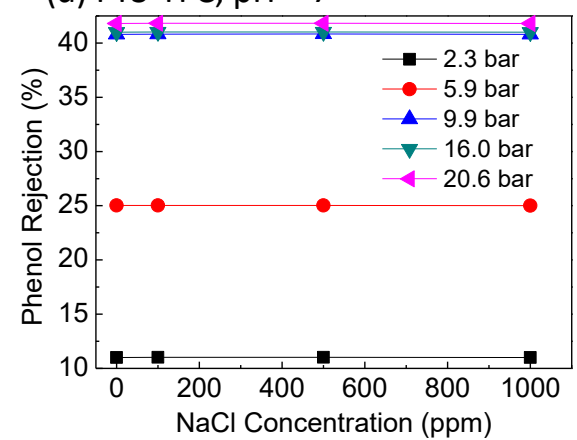

(f) Tailor-made-TFC; $\mathrm{pH}=7$

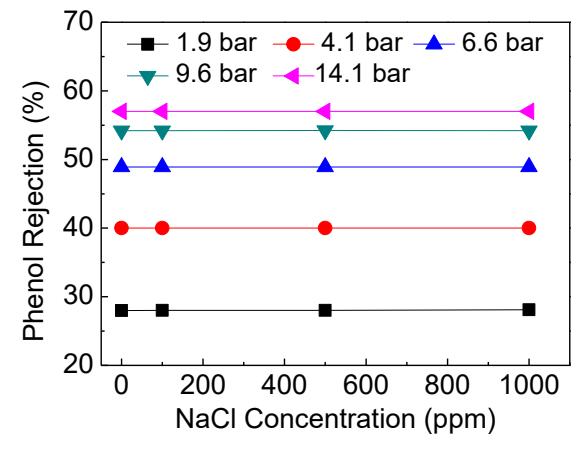

Fig. 4 Fluxes and phenol rejections of FTS-CTA, FTS-TFC and Tailor-made-TFC membranes at pH = 7, different feed solutions and operating pressures; (a) and (b) FTS-CTA membrane; 9.3-18.1 bar; (c) and (d) FTS-TFC membrane; 2.3-20.6 bar; (e) and (f) Tailor-made-TFC membrane; 1.9-14.1 bar; the feeds of (b), (d), and (f) were different $\mathrm{NaCl}$ concentrations added into 100 ppm phenol, respectively; 
(a) FTS-TFC; $\mathrm{pH}=11$

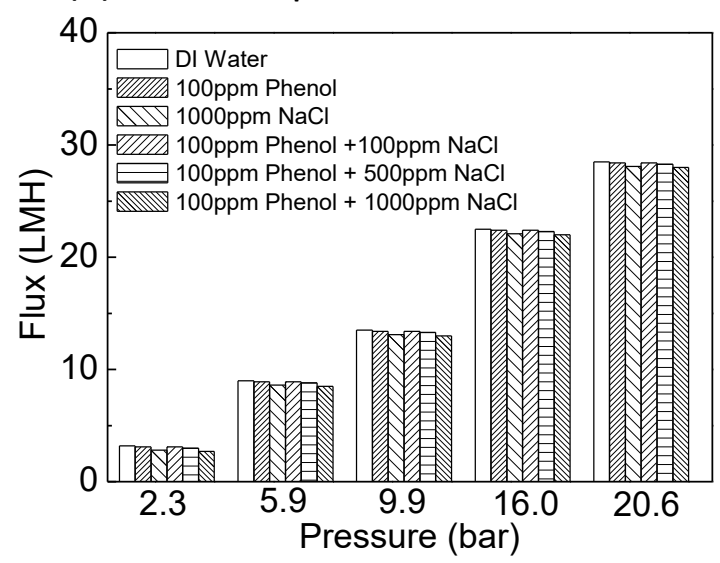

(c) Tailor-made-TFC; $\mathrm{pH}=11$

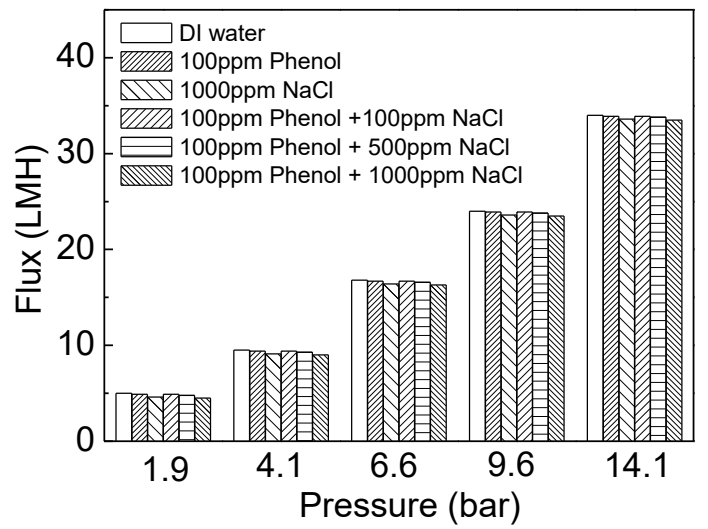

(b) FTS-TFC; $\mathrm{pH}=11$

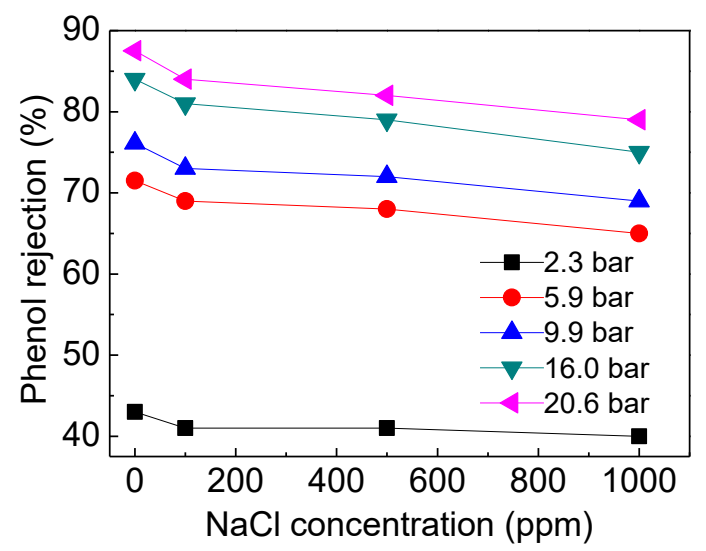

(d) Tailor-made-TFC; $\mathrm{pH}=11$

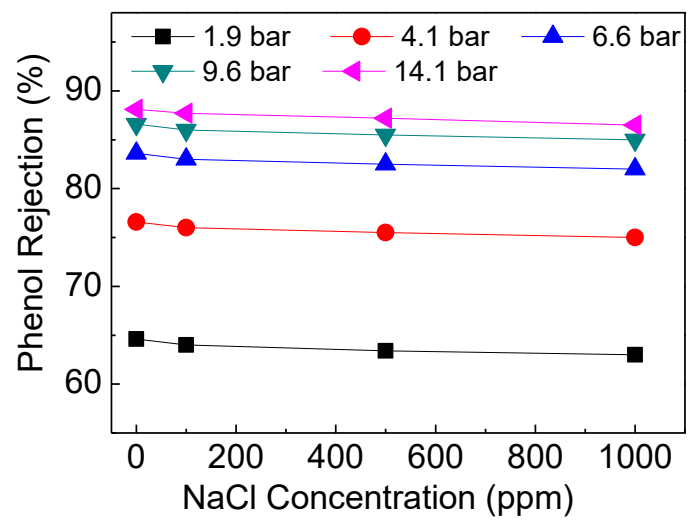

Fig. 5 Fluxes and phenol rejections of FTS-TFC and Tailor-made-TFC membranes at pH = 11; the feeds were at $\mathrm{pH}=11$; other operation conditions were the same as Fig. 4 (c)-(f).

\subsection{Modelling the transport of phenol in RO process}

The irreversible thermodynamic model was used to further elucidate the rejection behaviors of phenol in RO mode. From the observed rejection data and the mass transfer coefficient $(k)$, the real rejection $\left(R_{\text {real }}\right)$ at different permeate flux were calculated using Eq. (12). The reflection coefficient $(\sigma)$ and solute permeability coefficient $\left(P_{s}\right)$ were obtained by fitting the real rejection data to the irreversible thermodynamic model (Eqs. 9, 10) and the data were summarized in Table 2. The irreversible thermodynamic model could describe very well the rejection of phenol by FTS-TFC, FTS-CTA, and tailor-made-TFC membranes under all experimental conditions (Fig. 6). The reflection coefficient $(\sigma)$ of TFC membrane was higher than that of CTA membrane, and increased at higher feed $\mathrm{pH}$, especially for tailor-made-TFC. Consequently, TFC membrane showed lowest solute permeability coefficient (Ps) at pH = 11 (Table 2). 


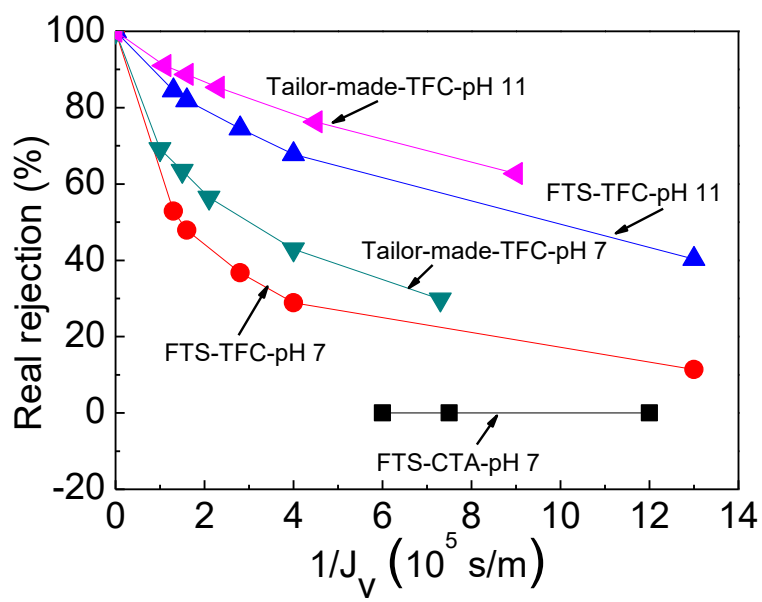

Fig. 6 Real phenol rejections of by FTS-TFC, FTS-CTA and tailor-made-TFC membranes as a function of reciprocal permeate flux. Feed: 100 ppm phenol +1000 ppm NaCl (feed in $\mathrm{pH}=7$ and $\mathrm{pH}=11$ ); for CTA membrane, the operational pressures were 9.3-18.1 bars; for FTS-TFC membrane, the pressures were 2.3-20.6 bars; for tailor-made-TFC membrane, the pressures were 1.9-14.1 bars.

Table 2 Transport parameters of phenol through the FTS-TFC, FTS-CTA, and tailor-made-TFC membranes and the fitting coefficient of determination $\left(R^{2}\right)$ of the irreversible thermodynamics model.

\begin{tabular}{cccc}
\hline Membrane & $\boldsymbol{\sigma}[-](95 \%$ confidence bounds) & $P s[\mathrm{~m} / \mathrm{s}](95 \%$ confidence bounds) & $\boldsymbol{R}^{2}[-]$ \\
\hline FTS-CTA $(\mathbf{p H}=7)$ & $0.001(0,0.0011)$ & $9.0 \times 10^{-6}\left(6 \times 10^{-6}, 1.7 \times 10^{-7}\right)$ & 0.99 \\
\hline FTS-TFC $(\mathbf{p H}=7)$ & $0.772(0.73,0.81)$ & $4.4 \times 10^{-6}\left(4 \times 10^{-6}, 4.8 \times 10^{-6}\right)$ & 0.99 \\
\hline Tailor-made-TFC & $0.820(0.86,0.79)$ & $2.5 \times 10^{-6}\left(2.3 \times 10^{-6}, 2.6 \times 10^{-6}\right)$ & 0.99 \\
(pH = 7) & $0.925(0.97,0.87)$ & $1.0 \times 10^{-6}\left(1.1 \times 10^{-6}, 9.5 \times 10^{-5}\right)$ & 0.99 \\
\hline FTS-TFC (pH = 11) & $0.95(0.99,0.92)$ & $0.6 \times 10^{-6}\left(0.4 \times 10^{-6}, 0.8 \times 10^{-5}\right)$ & 0.99 \\
\hline Tailor-made-TFC & & &
\end{tabular}

\subsection{Comparison of phenol rejection in FO and RO modes}

\subsubsection{Phenol rejection in FO and RO modes}

Fig. 7 shows the relationship between the rejection and flux in both RO and FO mode, for FTS-CTA, FTS-TFC and tailor-made-TFC membranes (feed $\mathrm{pH}=7$ ). The low water permeability of CTA membranes 

phenol.

(a) FTS-CTA

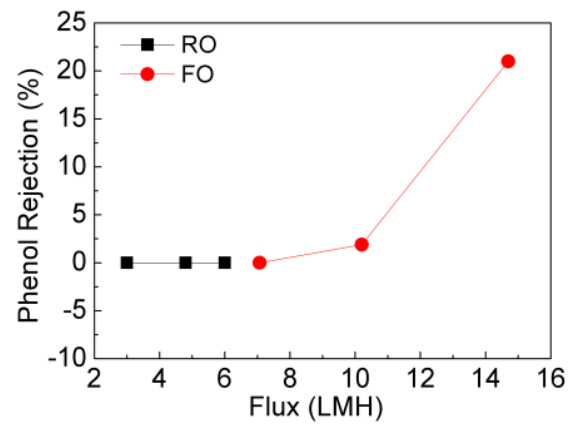

(b) FTS-TFC

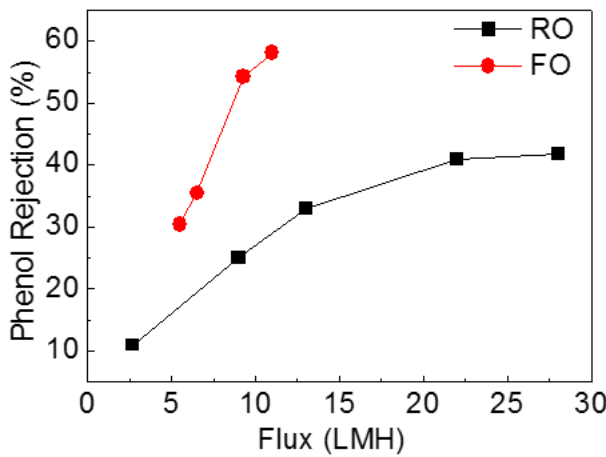

(c) Tailor-made-TFC

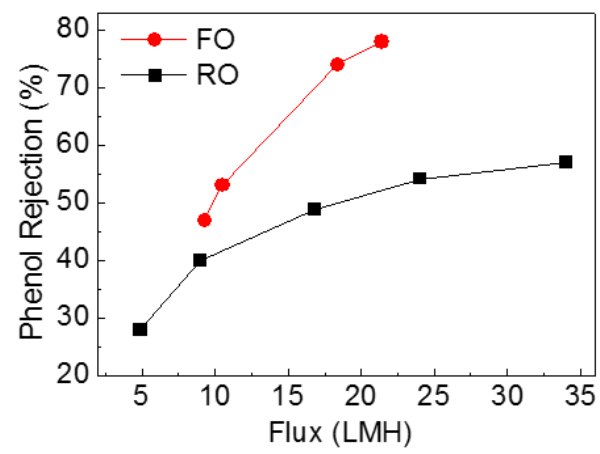

Fig. 7 Phenol rejection by the (a) FTS-CTA (b) FTS-TFC (c) tailor-made-TFC membranes at various water fluxes. In FO mode, for FTS-CTA membrane, the draw were 1-4 mol/L; for FTS-TFC and tailor-made-TFC membranes, the draw were 0.5-4 mol/L. In RO mode, the operation conditions were showed in Fig. 6 . All solutions were at $\mathrm{pH}=7$; solution temperature was maintained at $25 \pm 1{ }^{\circ} \mathrm{C}$.

\subsubsection{Sorption and diffusion of phenol in CTA and TFC membranes}

Phenol sorption in the CTA and PA active layers was systematically quantified to elucidate their different separation capacity toward phenol (Fig. 8). Phenol adsorption to the CTA active layer $\left(40 \mathrm{mg} / \mathrm{m}^{2}\right)$ was much higher than that to the PA active layer $\left(2.07 \mathrm{mg} / \mathrm{m}^{2}\right)$. Lower adsorption than the reported work by Schutte [14]. The phenol adsorption in PSf support layer was observed to be $54 \mathrm{mg} / \mathrm{m}^{2}$, much higher than CTA membranes. However, in RO or FO modes, the PSf support do not directly contact with the feed 
solution. In reality, the actual absorbed phenol in the PSf support would be significantly lower, and detailed sorption data for TFC and CTA membranes can be seen in Table S2. In a recent report, comparison of the adsorption of phenol for CTA and TFC membrane in FO mode confirmed that the adsorption of phenol strongly affected the rejection behavior of phenol [25]. Due to the strong "solute-membrane affinity", the CTA membranes had higher sorption capacity resulting in a much lower rejection than that by the TFC PA membranes. Phenol transport through the membrane is governed by sorption-diffusion. Dynamic analysis of the phenol rejection by CTA and TFC membranes is described below: (1) at first, there exists an initial absorption and sorption dominates the rejection, leading to a temporarily higher initial rejection; (2) once the sorption capacity of the membrane is exhausted, rejection is dominated by diffusion. Indeed, declining rejection by nanofiltration membranes over time due to sorption-diffusion has been observed for organic compounds containing phenolic groups $[18,19]$.

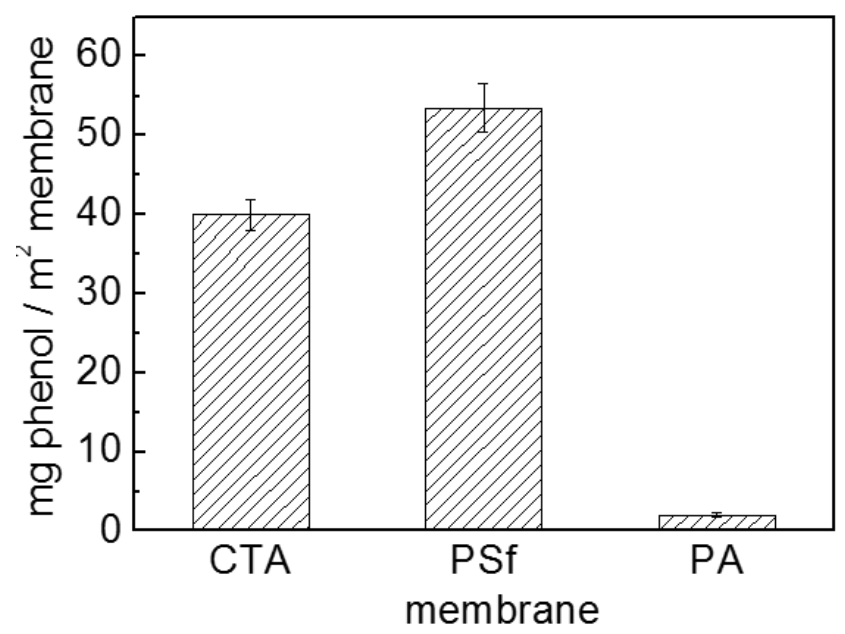

Fig. 8 Adsorption capacity of FTS-CTA and TFC-tailor made membranes and only the PSf-tailor made supporting layer (error bars show the standard deviation of three experimental measurements).

CTA membranes are cellulose-based with acetyl and hydroxyl functional groups that are non-ionogenic, however, TFC membrane surface is aromatic polyamide chains, which showed ionizable carboxyl groups [41]. Phenol has a stronger hydrogen bonding attraction with hydroxyl functional groups than carboxyl groups [21]. For CTA membranes, the solute-membrane attraction dominated over the water-membrane attraction and no rejection actually occurred. However, for TFC membranes, besides the weaker attraction, the thickness of the active PA layer was much thinner than cellulose triacetate layer, which meant much lower adsorption load of phenol occurred in the TFC active layer. In addition, former reported research indicated CTA membrane showed higher diffusion flux than TFC membrane [14]. Quantitatively, the phenol 
permeability in the CTA $\left(9.0 \times 10^{-6} \mathrm{~m} / \mathrm{s}\right)$ was found to be higher than that in FTS-TFC membrane $\left(4.4 \times 10^{-6}\right.$ $\mathrm{m} / \mathrm{s})$ and tailor-made-TFC membrane $\left(2.5 \times 10^{-6} \mathrm{~m} / \mathrm{s}\right)$ (Table 2). Hence, the low rejection of CTA membrane for phenol than TFC membrane is a combination of higher adsorption and diffusion.

\subsection{Further improvement in the phenol rejection}

Fig. 7 showed higher rejection to phenol in FO using TFC membrane, however, the rejection rate was still low, for FTS-TFC about $60 \%$ and for tailor-made-TFC membrane about $78 \%$ at a feed $\mathrm{pH}=7$. Fig. 5 showed improved phenol rejection above $80 \%$ using FTS-TFC and tailor-made-TFC membranes at a feed pH $=11$ in RO mode. Combining the beneficiary factors of feed $\mathrm{pH}$ and FO, further improvement in the phenol rejection is probable. Fig. 9 (a) and (b) showed the relation between the rejections and flux in both RO and FO modes for FTS-TFC and tailor-made-TFC membranes at $\mathrm{pH}=7$, and 11. For FTS-TFC membrane, the phenol rejection increased from $89 \%$ at $5 \mathrm{~L} / \mathrm{m}^{2} \mathrm{~h}$ to $94.5 \%$ at $11 \mathrm{~L} / \mathrm{m}^{2} \mathrm{~h}$; and for tailor-made-TFC membrane, the phenol rejection increased from $90 \%$ at $9 \mathrm{~L} / \mathrm{m}^{2} \mathrm{~h}$ to $96.7 \%$ at $21.4 \mathrm{~L} / \mathrm{m}^{2} \mathrm{~h}$. The mechanism for the improved rejection to phenol at pH = 11 in FO mode is schematically shown in Fig. 9 (c).

In FO mode, TFC membranes showed higher rejections than that of RO mode. That was mainly resulted from the reverse salt flux, phenol molecules and the salt diffused at the reverse directions, reverse salt hindered the diffusion of the phenol within the membrane pores, leading to reduced phenol diffusion across the active layer in FO mode [45]. The second factor is the feed pH value; at $\mathrm{pH} 11$, phenolate exists a negatively charged; negatively charged TFC active layer further repulses the negatively charged phenolate species, resulting in a dramatically increased phenol rejection. In conclusion, TFC membrane in FO mode is preferred for treating the phenol solution, especially adjusting the neutral solution to alkaline. 
(a) FTS-TFC

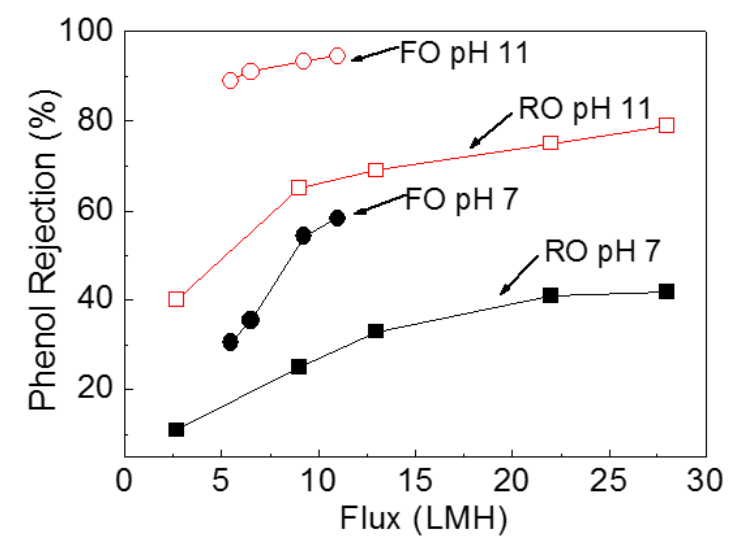

(b) Tailor-made-TFC

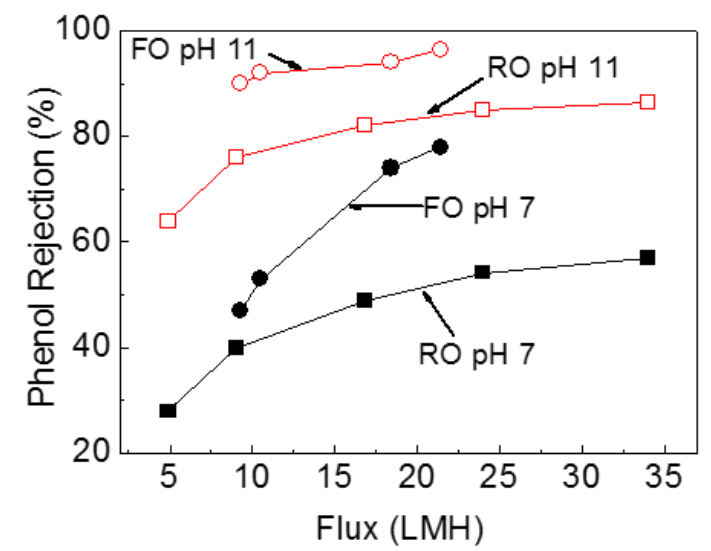

(c) schematic diagram of higher phenol rejection in FO mode

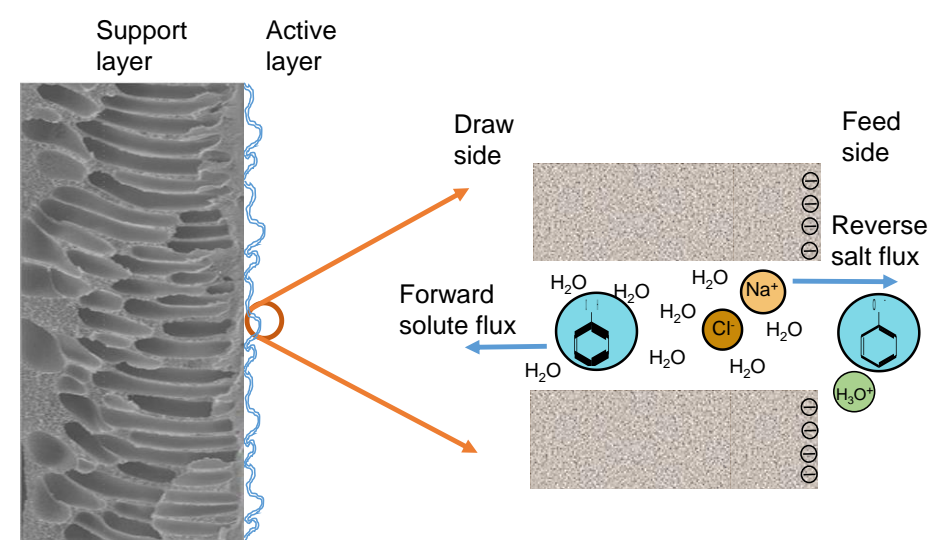

Fig. 9 (a) phenol rejections of FTS-TFC membrane (b) tailor-made-TFC membrane at various water fluxes and different $\mathrm{pH}(\mathrm{c})$ schematic diagram of higher phenol rejection in $\mathrm{FO}$ mode by reverse salt flux and electrostatic repulsive force between membrane and phenolate. (a) Feed: 100 ppm phenol +1000 ppm $\mathrm{NaCl}$; the pressures were 2-20 bars, respectively in $\mathrm{RO}$, and the draw were $0.5-4 \mathrm{~mol} / \mathrm{L}$ in FO; solution temperature was maintained at $25 \pm 1^{\circ} \mathrm{C}$.

\section{Conclusions}

The separation of phenol via RO and FO modes was investigated systematically, and the strategies to enhance phenol rejection by the two process were proposed. The results showed that water flux, membrane materials, membrane structure, modes of operation, and feed solution chemistry (i.e. $\mathrm{pH}$ ) were the factor which could strongly influenced phenol rejection. And the rejection-flux performance was accurately modeled based on the irreversible thermodynamic theory. At $\mathrm{pH}$ 7, the thin film composite (TFC) polyamide (PA) membranes exhibited much higher phenol rejection than that of cellulose acetate (CTA) membranes. Static adsorption experiment showed that phenol adsorption to CTA material was about 20 
times higher than that to PA material. Thus, the higher affinity of phenol toward CTA and the sorption diffusion transport mechanism of phenol through the membrane resulted in the lower observed phenol rejection. For TFC membranes, at the same water flux and solution $\mathrm{pH}$, the phenol rejection in FO mode was higher than in RO mode, tailor-made TFC membrane was slightly higher than the commercial TFC membrane, which probably attributed to the retarded forward diffusion to hinder the forward diffusion of phenol within the membrane pores. Further increase in the phenol rejection was achieved by increasing the feed $\mathrm{pH}$ above the dissociation constant due to the charge repulsion.

\section{Acknowledgments}

The authors thank National Natural Science Foundation of China (U1507117, 21676290), Disney

Research Funding (Contract No. CA1501), TMSR from Chinese Academy of Sciences (XDA02020100), Key Research Fund (CAS2014 Y424541211) for partial financial support and VISA Fellowship of University of

Wollongong is highly appreciated.

\section{References}

[1] V.L. Santos, V.R. Linardi, Biodegradation of phenol by a filamentous fungi isolated from industrial effluents - identification and degradation potential, Process Biochemistry, 39 (2004) 1001-1006.

[2] B. Marrot, A. Barrios-Martinez, P. Moulin, N. Roche, Biodegradation of high phenol concentration by activated sludge in an immersed membrane bioreactor, Biochemical Engineering Journal, 30 (2006) 174-183.

[3] A. Bodalo, J.L. Gomez, M. Gomez, G. Lenon, A.M. Hidalgo, M.A. Ruiz, Phenol removal from water by hybrid processes: study of the membrane process step, Desalination, 223 (2008) 323-329.

[4] Y. Li, J. Wei, C. Wang, W. Wang, Comparison of phenol removal in synthetic wastewater by NF or RO membranes, Desalin. Water Treat., 22 (2012) 211-219.

[5] T. Matsuura, S. Sourirajan, Physicochemical criteria for reverse osmosis separation of alcohols, phenols, and monocarboxylic acids in aqueous solutions using porous cellulose acetate membranes, Journal of Applied Polymer Science, 15 (1971) $2905-2927$.

[6] T. Matsuura, Souriraj.S, Reverse osmosis separation of phenols in aqueous-solutions using porous cellulose-acetate membranes, Journal of Applied Polymer Science, 16 (1972) 2531-2554.

[7] H.K. Lonsdale, U. Merten, M. Tagami, Phenol transport in cellulose acetate membranes, Journal of Applied Polymer Science, 11 (1967) 1807-1820.

[8] M.J. López-Muñoz, A. Sotto, J.M. Arsuaga, B. Van der Bruggen, Influence of membrane, solute and solution properties on the retention of phenolic compounds in aqueous solution by nanofiltration membranes, Sep. Purif. Technol., 66 (2009) $194-201$.

[9] D. Tabassi, A. Mnif, B. Hamrouni, Influence of operating conditions on the retention of phenol in water by reverse osmosis SG membrane characterized using Speigler-Kedem model, Desalin. Water Treat., 52 (2013) 1792-1803.

[10] P. Connell, J.M. Dickson, Modeling reverse-osmosis separation with strong solute-membrane affinity at different temperatures using the finely porous model, Journal of Applied Polymer Science, 35 (1988) 1129-1148.

[11] B. Van der Bruggen, J. Schaep, D. Wilms, C. Vandecasteele, Influence of molecular size, polarity and charge on the retention 
of organic molecules by nanofiltration, Journal of Membrane Science, 156 (1999) 29-41.

[12] B. Van der Bruggen, L. Braeken, C. Vandecasteele, Evaluation of parameters describing flux decline in nanofiltration of aqueous solutions containing organic compounds, Desalination, 147 (2002) 281-288.

[13] T. Kataoka, T. Nishiki, S. Kimura, Phenol permeation through liquid surfactant membrane-permeation model and effective diffusive, Journal of Membrane Science, 41 (1989) 197-209.

[14] C.F. Schutte, The rejection of specific organic compounds by reverse osmosis membranes, Desalination, 158 (2003) 285-294.

[15] U. Ipek, Phenol removal capacity of RO with and without pre-treatment, Filtration \& Separation, 41 (2004) 39-40.

[16] J. Song, M. Zhang, A. Figoli, Y. Yin, B. Zhao, X.-M. Li, T. He, Arsenic removal using a sulfonated poly(ether ether ketone) coated hollow fiber nanofiltration membrane, Environmental Science-Water Research \& Technology, 1 (2015) 839-845.

[17] J. Song, X.-M. Li, Z. Li, M. Zhang, Y. Yin, B. Zhao, D. Kong, G. Chen, T. He, Stabilization of composite hollow fiber nanofiltration membranes with a sulfonated poly(ether ether ketone) coating, Desalination, 355 (2015) 83-90.

[18] L.D. Nghiem, A.I. Schafer, M. Elimelech, Removal of natural hormones by nanofiltration membranes: Measurement, modeling, and mechanisms, Environmental science \& technology, 38 (2004) 1888-1896.

[19] K. Kimura, G. Amy, J. Drewes, Y. Watanabe, Adsorption of hydrophobic compounds onto NF/RO membranes: an artifact leading to overestimation of rejection, Journal of Membrane Science, 221 (2003) 89-101.

[20] A.R.D. Verliefde, E.R. Cornelissen, S.G.J. Heijman, E.M.V. Hoek, G.L. Amy, B. Van Der Bruggen, J.C. Van Dijk, Influence of Solute-Membrane Affinity on Rejection of Uncharged Organic Solutes by Nanofiltration Membranes, Environmental science \& technology, 43 (2009) 2400-2406.

[21] A.L. Ahmad, K.Y. Tan, Reverse osmosis of binary organic solute mixtures in the presence of strong solute-membrane affinity, Desalination, 165 (2004) 193-199.

[22] J. Song, X.-M. Li, A. Figoli, H. Huang, C. Pan, T. He, B. Jiang, Composite hollow fiber nanofiltration membranes for recovery of glyphosate from saline wastewater, Water research, 47 (2013) 2065-2074.

[23] D.L. Shaffer, N.Y. Yip, J. Gilron, M. Elimelech, Seawater desalination for agriculture by integrated forward and reverse osmosis: Improved product water quality for potentially less energy, Journal of Membrane Science, 415 (2012) 1-8.

[24] Y. Cui, X.Y. Liu, T.S. Chung, M. Weber, C. Staudt, C. Maletzko, Removal of organic micro-pollutants (phenol, aniline and nitrobenzene) via forward osmosis (FO) process: Evaluation of FO as an alternative method to reverse osmosis (RO), Water research, 91 (2016) 104-114.

[25] J. Heo, L.K. Boateng, J.R.V. Flora, H. Lee, N. Her, Y.G. Park, Y. Yoon, Comparison of flux behavior and synthetic organic compound removal by forward osmosis and reverse osmosis membranes, Journal of Membrane Science, 443 (2013) 69-82.

[26] J.M. Arsuaga, M.J. López-Muñoz, A. Sotto, Correlation between retention and adsorption of phenolic compounds in nanofiltration membranes, Desalination, 250 (2010) 829-832.

[27] A. Sotto, J.M. Arsuaga, B. Van der Bruggen, Sorption of phenolic compounds on NF/RO membrane surfaces: Influence on membrane performance, Desalination, 309 (2013) 64-73.

[28] P. Xiao, L.D. Nghiem, Y. Yin, X.-M. Li, M. Zhang, G. Chen, J. Song, T. He, A sacrificial-layer approach to fabricate polysulfone support for forward osmosis thin-film composite membranes with reduced internal concentration polarisation, Journal of Membrane Science, 481 (2015) 106-114.

[29] G. Chen, Z. Wang, L.D. Nghiem, X.-M. Li, M. Xie, B. Zhao, M. Zhang, J. Song, T. He, Treatment of shale gas drilling flowback fluids (SGDFs) by forward osmosis: Membrane fouling and mitigation, Desalination, 366 (2015) 113-120.

[30] G. Chen, R. Liu, H.K. Shon, Y. Wang, J. Song, X.-M. Li, T. He, Open porous hydrophilic supported thin-film composite forward osmosis membrane via co-casting for treatment of high-salinity wastewater, Desalination, 405 (2017) 76-84.

[31] G. Chen, Z.W. Wang, X.M. Li, J.F. Song, B.L. Zhao, S. Phuntsho, H.K. Shon, T. He, Concentrating underground brine by FO process: Influence of membrane types and spacer on membrane scaling, Chemical Engineering Journal, 285 (2016) 92-100.

[32] T.Y. Cath, M. Elimelech, J.R. McCutcheon, R.L. McGinnis, A. Achilli, D. Anastasio, A.R. Brady, A.E. Childress, I.V. Farr, N.T. Hancock, J. Lampi, L.D. Nghiem, M. Xie, N.Y. Yip, Standard Methodology for Evaluating Membrane Performance in Osmotically Driven Membrane Processes, Desalination, 312 (2013) 31-38.

[33] S. Loeb, L. Titelman, E. Korngold, J. Freiman, Effect of porous support fabric on osmosis through a Loeb-Sourirajan type asymmetric membrane, Journal of Membrane Science, 129 (1997) 243-249. 
[34] J.R. McCutcheon, M. Elimelech, Influence of membrane support layer hydrophobicity on water flux in osmotically driven membrane processes, Journal of Membrane Science, 318 (2008) 458-466.

[35] O. Kedem, A. Katchalsky, Permeability of composite membranes. Part1- electric current, volume flow and flow of solute through membranes, Trans. Faraday Soc, 59 (1963) 1918-1930.

[36] T. Fujioka, L.D. Nghiem, S.J. Khan, J.A. McDonald, Y. Poussade, J.E. Drewes, Effects of feed solution characteristics on the rejection of N-nitrosamines by reverse osmosis membranes, Journal of Membrane Science, 409-410 (2012) 66-74.

[37] T. Tsuru, S. Izumi, T. Yoshioka, M. Asaeda, Temperature Effect on Transport Performance by inorganic nanofiltration membrane, AIChE J, 46 (2000) 565-574.

[38] T. Tsuru, K. Ogawa, M. Kanezashi, T. Yoshioka, Permeation Characteristics of Electrolytes and Neutral Solutes through Titania Nanofiltration Membranes at High Temperatures, Langmuir : the ACS journal of surfaces and colloids, 26 (2010) $10897-10905$.

[39] F.A. Pacheco, I. Pinnau, M. Reinhard, J.O. Leckie, Characterization of isolated polyamide thin films of RO and NF membranes using novel TEM techniques, Journal of Membrane Science, 358 (2010) 51-59.

[40] P.S. Singh, A.P. Rao, P. Ray, A. Bhattacharya, K. Singh, N.K. Saha, A.V.R. Reddy, Techniques for characterization of polyamide thin film composite membranes, Desalination, 282 (2011) 78-86.

[41] B.D. Coday, T. Luxbacher, A.E. Childress, N. Almaraz, P. Xu, T.Y. Cath, Indirect determination of zeta potential at high ionic strength: Specific application to semipermeable polymeric membranes, Journal of Membrane Science, 478 (2015) 58-64.

[42] N.M. Mazlan, P. Marchetti, H.A. Maples, B. Gu, S. Karan, A. Bismarck, A.G. Livingston, Organic fouling behaviour of structurally and chemically different forward osmosis membranes - A study of cellulose triacetate and thin film composite membranes, Journal of Membrane Science, 520 (2016) 247-261.

[43] T. He, M. Frank, M.H.V. Mulder, M. Wessling, Preparation and characterization of nanofiltration membranes by coating polyethersulfone hollow fibers with sulfonated poly(ether ether ketone) (SPEEK), Journal of Membrane Science, 307 (2008) 62-72.

[44] L.D. Nghiem, A.I. Schafer, M. Elimelech, Role of electrostatic interactions in the retention of pharmaceutically active contaminants by a loose nanofiltration membrane, Journal of Membrane Science, 286 (2006) 52-59.

[45] M. Xie, L.D. Nghiem, W.E. Price, M. Elimelech, Comparison of the removal of hydrophobic trace organic contaminants by forward osmosis and reverse osmosis, Water research, 46 (2012) 2683-2692. 